\title{
METODE PEMBELAJARAN BAHASA JEPANG TINGKAT DASAR BERBASIS MULTIMEDIA MENGGUNAKAN MACROMEDIA FLASH MX
}

\author{
Sapri, Indra Kanedi \\ ${ }^{2}$ DosenTetap Program Studi Informatika Fakultas Ilmu Komputer Universitas Dehasen Bengkulu \\ Jl. Meranti Raya No. 32 Kota Bengkulu 38228 Telp. (0736) 22027, 26957 Fax. (0736) 341139) \\ Email : saprikubaru@yahoo.co.id indrakanedi12@gmail.com
}

\begin{abstract}
Learning Methods for Basic Japanese Language Based on Multimedia Using Macromedia Flash MX (2010). This study aims to create a basic level Japanese learning method at LP2M El Rahma Bengkulu by using Macromedia Flash MX, in order to make it easier for teachers, students and students to learn basic Japanese so as to increase interest and attractiveness in learning Japanese.

The research was conducted at LP2M El Rahma Bengkulu, which is located at Jalan Kemang Manis No.10 Sawah Lebar Bengkulu Tel. (0736) 22123 Bengkulu. The research was conducted from March to July 2010. The problem in this study is how to make Japanese language learning methods at the basic level using Macromedia Flash MX. So that it can be useful for El Rahma Bengkulu and students and students of course.

Based on the results and discussion as well as the results of the system testing, it can be concluded that in making this Japanese language learning method at LP2M El Rahma Bengkulu, first making a system design, this software was created using Macromedia Flash MX. So that it has an attractive appearance and gets good results.

Keywords: Japanese Language Learning Methods at The Basic Level.
\end{abstract}

Intisari : Metode Pembelajaran Bahasa Jepang Tingkat Dasar Berbasis Multimedia Menggunakan Macromedia Flash MX (2010). Penelitian ini bertujuan untuk membuat metode pembelajaran bahasa jepang tingkat dasar pada LP2M El Rahma Bengkulu dengan menggunakan Macromedia Flash $M X$, agar mempermudah pengajar, siswa dan mahasiswa dalam mempelajari bahasa jepang tingkat dasar sehingga menambah minat dan daya tarik dalam belajar bahasa jepang.

Penelitian dilaksanakan di LP2M El Rahma Bengkulu, yang beralamatkan di Jalan Kemang Manis No.10 Sawah Lebar Bengkulu Telp.(0736) 22123 Bengkulu. Penelitian dilaksanakan dari bulan Maret sampai Juli 2010. Permasalahan dalam Penelitian ini adalah bagaimana membuat metode pembelajaran bahasa jepang tingkat dasar menggunakan Macromedia Flash $M X$. Sehingga dapat bermanfaat bagi El Rahma Bengkulu dan siswa dan mahasiswa tentunya.

Berdasarkan hasil dan pembahasan serta hasil dari pengujian sistem, dapat ditarik kesimpulan bahwa dalam membuat metode pembelajaran bahasa jepang ini pada LP2M El Rahma Bengkulu terlebih dahulu membuat perancangan sistem, Software ini di buat dengan menggunakan Macromedia Flash $M X$. Sehingga memiliki tampilan yang menarik dan mendapatkan hasil yang baik.

Kata Kunci : Metode Pembelajaran Bahasa Jepang Tingkat Dasar.

\section{PENDAHULUAN}

\section{A. Latar Belakang}

Seiring dengan perkembangan zaman sekarang ini, yang kian lama kian berkembang dinamis, Komunikasi adalah salah satu hal vital dalam pendidikan.
Seorang pendidik guru atau dosen, sedang melakukan komunikasi dengan para siswa/mahasiswanya ketika proses belajar mengajar. Dengan komunikasi yang efektif, maka transfer ilmu dan nilai bisa berjalan efektif pula. Begitu pula sebaliknya, jika komunikasi tidak efektif, maka transfer ilmu dan nilai pun tidak akan optimal. Dampak yang terjadi misalnya siswa lambat dalam memahami pelajaran.

Berdasarkan penelitian De Porter, manusia dapat menyerap suatu materi sebanyak $70 \%$ dari apa yang dikerjakan, 50\% dari apa yang didengar dan dilihat (audio visual), sedangkan dari yang dilihatnya hanya 30\%, dari yang didengarnya hanya $20 \%$, dan dari yang dibaca hanya $10 \%$.

Dengan demikian peneliti tertarik untuk mengangkat studi kasus dalam permasalahan ini dengan memanfaatkan kecanggihan teknologi komputer, merancang "Metode Pembelajaran Bahasa Jepang Tingkat Dasar Berbasis Multimedia Menggunakan Macromedia Flash $M X^{\prime}$, agar proses Kegiatan Belajar Mengajar (KBM), mentransfer ilmu dan nilai berjalan lebih efektif serta optimal.

\section{TINJAUAN PUSTAKA}

\section{A. Metode Pembelajaran}

Metode berasal dari Bahasa Yunani "Methodos" yang berarti cara atau jalan yang ditempuh. Sehubungan dengan upaya ilmiah, maka metode menyangkut masalah cara kerja untuk dapat memahami objek yang menjadi sasaran ilmu yang bersangkutan. Fungsi metode berarti sebagai alat untuk mencapai tujuan. (Hamalik, 2001)

Metodologi mengajar adalah ilmu yang mempelajari cara-cara untuk melakukan aktivitas yang tersistem dari sebuah lingkungan yang terdiri dari pendidik dan peserta didik untuk saling berinteraksi 
dalam melakukan suatu kegiatan sehingga proses belajar berjalan dengan baik dalam arti tujuan pengajaran tercapai.

Agar tujuan pengajaran tercapai sesuai dengan yang telah dirumuskan oleh pendidik, maka perlu mengetahui, mempelajari beberapa metode mengajar, serta dipraktekkan pada saat mengajar.

Ada Beberapa metode mengajar dalam bahasa jepang antara lain :

1. Metode Ceramah (Preaching Method)

2. Diskusi (Discussion)

3. Demontrasi (Demonstration)

4. Ceramah Plus Demonstrasi dan Latihan

5. percobaan (Experimental)

6. Latihan Keterampilan (Drill)

7. Mengajar Beregu (Team Teaching)

8. Mengajar Sesama Teman (Peer teaching)

9. Pemecahan Masalah (Problem Solving)

10. Perancangan (Project)

11. Inquiry

12. Global (Ganze)

\section{B. Multimedia dan Animasi}

a. Multimedia

Multimedia diambil dari kata multi dan media. Multi berarti banyak dan media berarti media atau perantara. Multimedia adalah pemanfaatan komputer untuk membuat dan menggabungkan teks, grafik, audio, gambar bergerak (video dan animasi) dengan menggabungkan link yang memungkinkan pemakai melakukan navigasi, berinteraksi, berkreasi dan berkomunikasi.

Ada empat komponen penting multimedia. Pertama, komputer yang mengkoordinasikan apa yang dilihat dan didengar. Kedua, link yang menghubungkan pemakai dengan informasi. Ketiga, alat navigasi yang membantu pemakai menjelajah jaringan informasi yang saling terhubung. Keempat, multimedia menyediakan tempat kepada pemakai untuk mengumpulkan, memproses, dan mengkomunikasikan informasi dengan ide. (http://id.wikipedia.org/wiki/Multimedia)

b. Animasi

Animasi adalah suatu rangkaian gambar diam secara inbeethwin dengan jumlah yang banyak, bila kita proyeksikan akan terlihat seolah - olah hidup ( bergerak ), seperti yang pernah kita lihat film - film kartun di tevisi maupun dilayar lebarjadi Animasi kita simpulkan menghidupkan benda diam diproyeksikan menjadi bergerak.

Kita sudah sekian lama mengenal animasi malalui film - film kartun yang tayangkan di TV maupun VCD. Pada dasarnya film/ Video Animasi berupa rangkaian gambar secara in beetwin lalu diproyeksikan pada layar menjadi gerakan, nah gerakan inilah kita sebut Animasi.Diera teknologi saat ini banyak sekali sofwer sofwer computer yang mensuport pembuatan animasi seperti : Diretor, Adobe Imag redy, Flash, 3d studio max, ulead Cool 3D studio. Animasi tidak hanya untuk film kartun saja, dapat juga kita gunakan untuk media media pendidikan, inpormasi, dan media pengetahuan lainnya yang tidak dapat digangkau dengan life melalui kamera foto atau video, contoh misalnya membuat film proses terjadinya tsunami,atau proses terjadinya gerhana matahari, ini akan sulit ditempuh dengan pengambilan gambar langsung melalui kamera.(Suryanto, 2005:20)

\section{Tulisan Bahasa Jepang}

Tulisan bahasa Jepang berasal dari tulisan bahasa China (漢字/kanji) yang diperkenalkan pada abad keempat Masehi. Sebelum ini, orang Jepang tidak mempunyai sistem penulisan sendiri.

Tulisan Jepang terbagi kepada tiga:

1. aksara Kanji (漢字) yang berasal dari China

2. aksara Hiragana (ひらがな) dan

3. aksara Katakana (カタカナ); keduanya berunsur daripada tulisan kanji dan dikembangkan pada abad 
kedelapan Masehi oleh rohaniawan Buddha untuk membantu melafazkan karakter-karakter China.

Bahasa Asli Jepang yaitu berasal dari bahasa asli pemukim Jepang zaman dahulu disebut yamato kotoba (大和言葉 ) yang berarti kosa kata Yamato. Kosakata Jepang sebagian besar berakar atau berasal dari Cina disebut kango (漢語) yang masuk pada abad ke-5 lewat Semenanjung Korea. Jepang banyak mengadopsi kosakata dari bahasa Inggris, kata-kata adopsi ini umumnya ditulis menggunakan huruf katakana. Contoh: マイカー(maikaa - sama dengan pelafalan "my car") yang berarti "mobil saya".

\section{(http://id.wikipedia.org/wiki/Bahasa)}

\section{METODOLOGI PENELITIAN}

\section{A. Metode Penelitian}

Adapun metode penelitian yang digunakan adalah metode pengembangan yaitu bagaimana informasi dikembangkan, Lembaga Pendidikan dan Pengembangan Manajemen (LP2M) El Rahma Bengkulu dalam Pelajaran Bahasa Jepang masih secara manual dan memberikan penjelasan materi-materi dipapan tulis. Dengan membuat metode pembelajaran bahasa jepang Tingkat dasar, agar dapat membantu dalam belajar bahasa jepang sehingga diharapkan akan menambah minat para siswa, mahasiswa atau umum mengenal lebih jauh tentang bahasa jepang khusus yang dasarnya dan meningkatkan hasil belajar siswa, mahasiswa dan umum tersebut.

\section{HASIL DAN PEMBAHASAN}

\section{A. HASIL}

Metode pembelajaran bahasa Jepang Tingkat dasar berbasis multimedia ini secara keseluruhannya mudah untuk dijalankan karena pengguna tinggal mengklik deretan tombol-tombol menu pilihan yang telah ada saat aplikasi ini dijalankan. Berikut ini penjelasan tentang penggunaan sistem.

\section{B. Menu Pembuka}

Saat program pembelajaran bahasa Jepang dijalankan akan tampil tampilan menu pembuka dimana Metode pembelajaran bahasa jepang tingkat dasar Berbasis multimedia menggunakan Macromedia flash mx pada menu pembuka ini berisikan tulisan Belajar Bahasa Jepang. Di bawah tulisan animasi teks terdapat dua tombol, tombol pertama jika di klik akan tampil tulisan mulai yang berfungsi untuk masuk ke dalam menu utama. Tombol kedua merupakan tombol keluar, yang jika di klik maka akan keluar dari program tersebut.

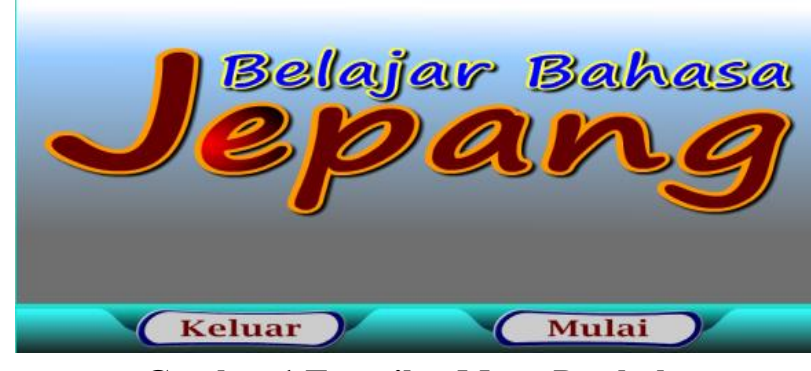

Gambar.1 Tampilan Menu Pembuka

\section{Menu Utama}

Pada menu utama terdapat animasi tulisan Belajar Bahasa Jepang, disampingnya terdapat logo El Rahma Bengkulu, dibelakangnya terdapat peta Negara Jepang. Pada menu utama ini terdapat 7 tombol, dimana terbagi menjadi 6 tombol untuk menuju ke submenu setiap materi pelajaran, tombol pertama menuju ke submenu Tata Bahasa, tombol kedua menuju ke submenu Mengenal Angka, tombol ketiga menuju ke submenu Mengenal Bulan, tombol keempat menuju ke submenu Mengenal Musim, tombol kelima menuju ke submenu Mengenal Hari, yang keenam menuju ke submenu Kebudayaan,. Dan Satu tombol yang terdapat dibawahnya merupakan tombol untuk kembali kemenu pembuka.

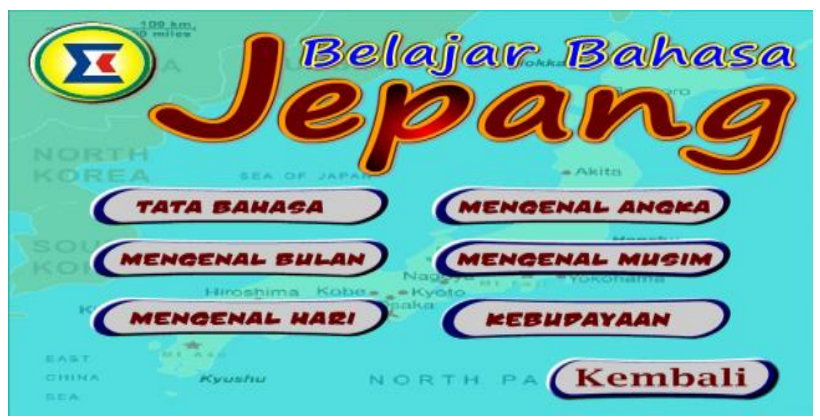

Gambar 2 Tampilan Menu Pembuka

\section{Sub Menu Tata Bahasa Jepang}

Pada sub Menu Tata Bahasa Jepang terdapat tulisan Tata Bahasa Jepang pada bagian atasnya. Pada sub menu ini terdapat 5 tombol yang masing-masing tombol tersebut adalah tombol huruf Kanji, untuk masuk ke sub menu huruf Kanji, tombol katana untuk masuk ke sub 
menu katakana, tombol Hiragana untuk masuk ke sub menu Hiragana, tombol Kembali untuk kembali ke Menu Utama, dan tombol Keluar untuk keluar dari Program. Pada bagian tengah menu ini berisikan penjelasan tentang Tata Bahasa Jepang.

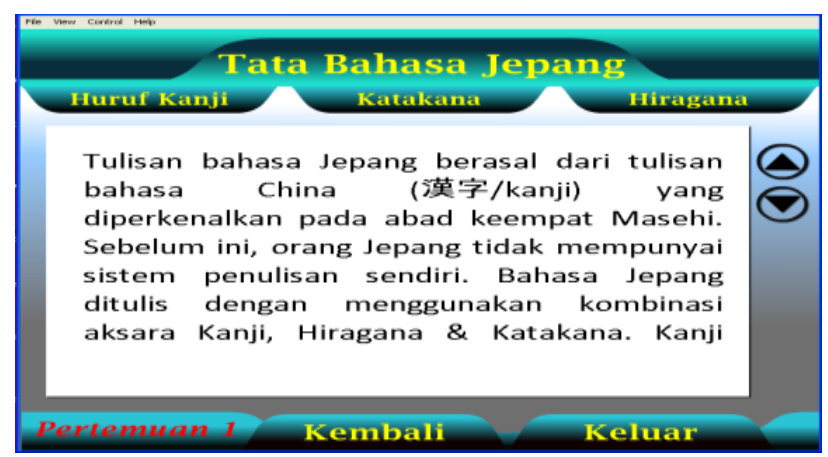

Gambar 3. Tampilan Menu Tata Bahasa

\section{E. Sub Menu Tata Bahasa Jepang Huruf Kanji}

Pada sub Menu Tata Bahasa Jepang Huruf Kanji terdapat tulisan Tata Bahasa Jepang pada bagian atasnya. Pada sub menu ini terdapat 5 tombol, yaitu tombol huruf Kanji, untuk masuk ke sub menu huruf Kanji, tombol Katana untuk masuk ke sub menu katakana, tombol Hiragana untuk masuk ke sub menu Hiragana, tombol Kembali untuk kembali ke Menu Utama, dan tombol Keluar untuk keluar dari Program. Pada bagian tengah menu ini berisikan penjelasan tentang Huruf Kanji

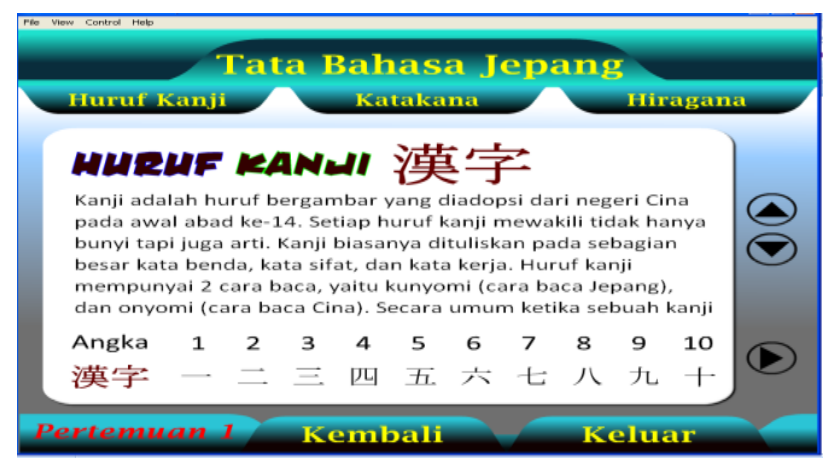

Gambar 4. Tampilan Sub Menu Tata Bahasa Jepang

$$
\text { Huruf Kanji. }
$$

\section{F.Sub Menu Tata Bahasa Jepang Huruf Katakana}

Pada sub Menu Tata Bahasa Jepang Huruf Katakana terdapat tulisan Tata Bahasa Jepang pada bagian atasnya. Pada sub menu ini terdapat 5 tombol, yaitu tombol huruf Kanji, untuk masuk ke sub menu huruf Kanji, tombol Katana untuk masuk ke sub menu katakana, tombol Hiragana untuk masuk ke sub menu Hiragana, tombol Kembali untuk kembali ke Menu Utama, dan tombol Keluar untuk keluar dari Program. Pada bagian tengah menu ini berisikan penjelasan tentang Huruf Katakana

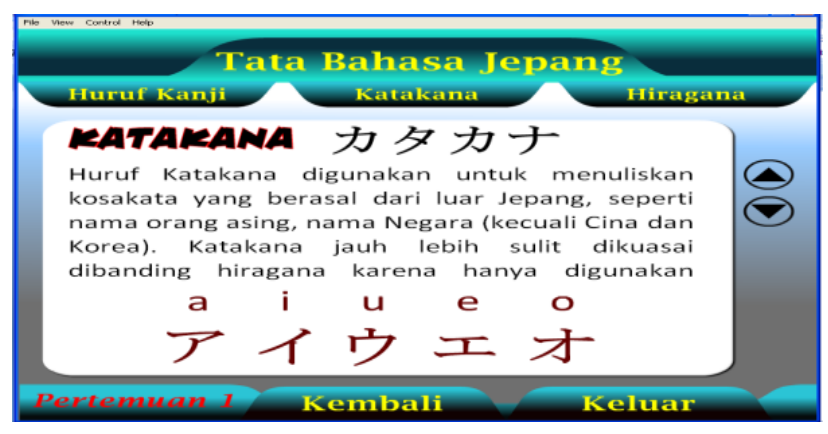

Gambar 5. Tampilan Sub Menu Huruf Katakana

\section{G. Sub Menu Tata Bahasa Jepang Huruf Hiragana}

Pada sub Menu Tata Bahasa Jepang Huruf Hiragana terdapat tulisan Tata Bahasa Jepang pada bagian atasnya. Pada sub menu ini terdapat 5 tombol, yaitu tombol huruf Kanji, untuk masuk ke sub menu huruf Kanji, tombol Katana untuk masuk ke sub menu katakana, tombol Hiragana untuk masuk ke sub menu Hiragana, tombol Kembali untuk kembali ke Menu Utama, dan tombol Keluar untuk keluar dari Program. Pada bagian tengah menu ini berisikan penjelasan tentang Huruf Hiragana.

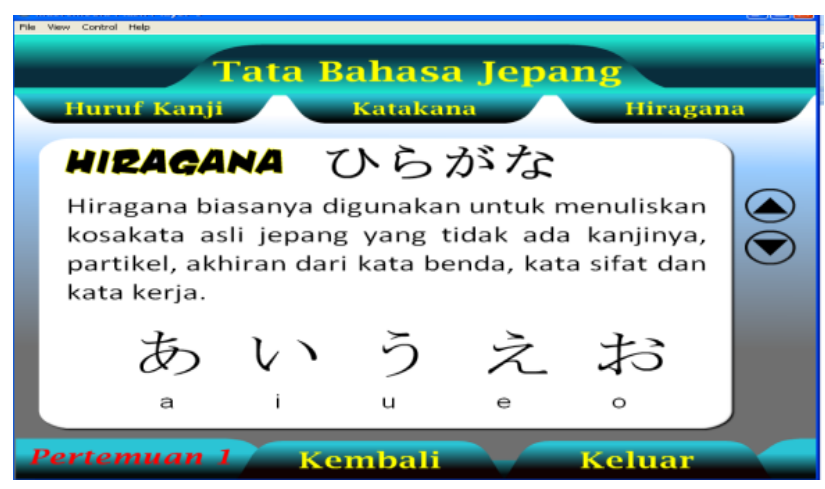

Gambar 6. Tampilan Sub Menu Huruf Hiragana

\section{H.Menu Mengenal Angka}

Pada Menu Mengenal Angka terdapat tulisan Mengenal Angka pada bagian atasnya, dibawahnya terdapat tulisan Mengenal Angka dalam Bahasa Jepang. Pada menu ini terdapat 16 tombol, yang terbagi atas dua bagian tombol 0 sampai tombol 50 untuk tombol masuk 
kedalam angka dalam bahasa Jepang, bagian kedua terdapat tombol Kembali, untuk kembali ke menu utama dan tombol keluar untuk keluar dari program.

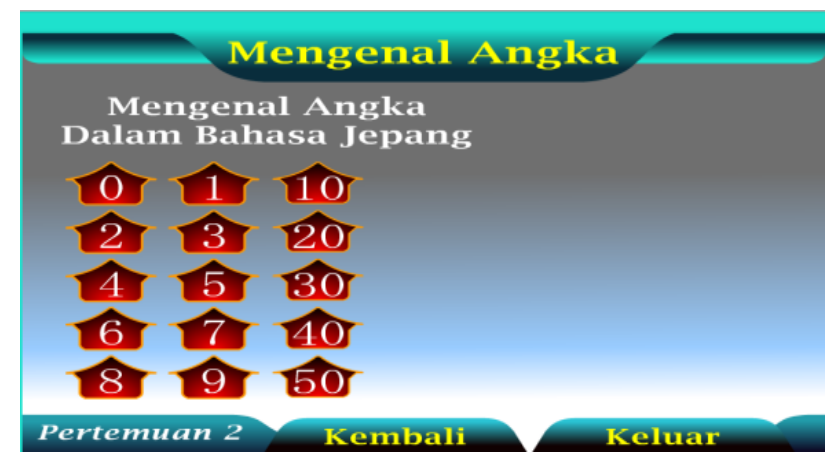

Gambar 7. Tampilan Menu Mengenal Angka.

\section{Sub Menu Mengenal Angka Nol}

Pada sub menu Mengenal Angka nol terdapat tulisan Mengenal Angka pada bagian atasnya, dibawahnya dibawahnya terdapat tulisan Mengenal Angka dalam Bahasa Jepang. Pada sub menu ini terdapat 16 tombol, yang terbagi atas dua bagian tombol 0 sampai tombol 50 untuk tombol masuk kedalam angka dalam bahasa Jepang, bagian kedua terdapat tombol Kembali, untuk kembali ke menu utama dan tombol keluar untuk keluar dari program. Pada bagian sebelah kanan terdapat penjelasan tentang angka nol dalam bahasa Jepang.

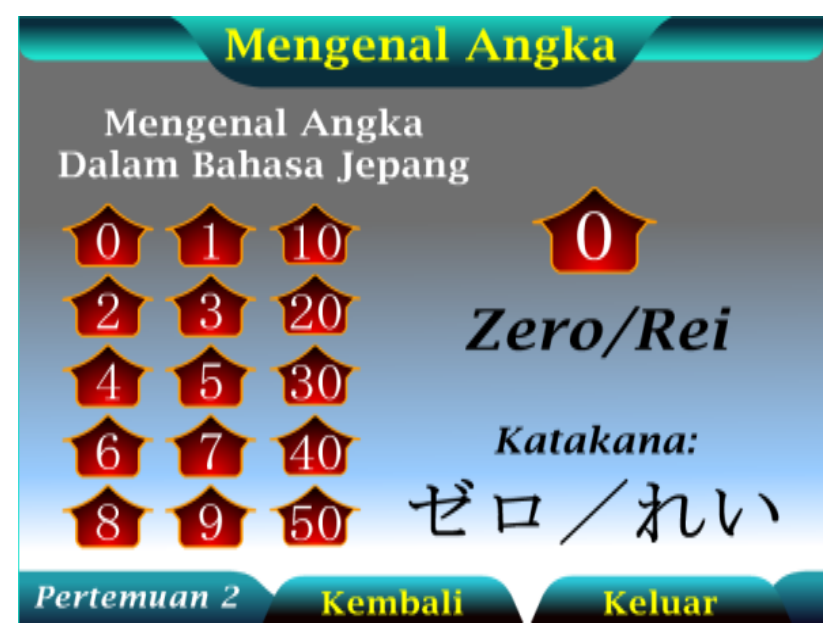

Gambar 8 Tampilan Sub Menu Mengenal Angka 0

\section{J.Sub Menu Mengenal Angka Satu}

Pada sub menu Mengenal Angka Satu terdapat tulisan Mengenal Angka pada bagian atasnya, dibawahnya dibawahnya terdapat tulisan Mengenal Angka dalam Bahasa Jepang. Pada sub menu ini terdapat 16 tombol, yang terbagi atas dua bagian tombol 0 sampai tombol 50 untuk tombol masuk kedalam angka dalam bahasa Jepang, bagian kedua terdapat tombol Kembali, untuk kembali ke menu utama dan tombol keluar untuk keluar dari program. Pada bagian sebelah kanan terdapat penjelasan tentang angka Satu dalam bahasa Jepang.

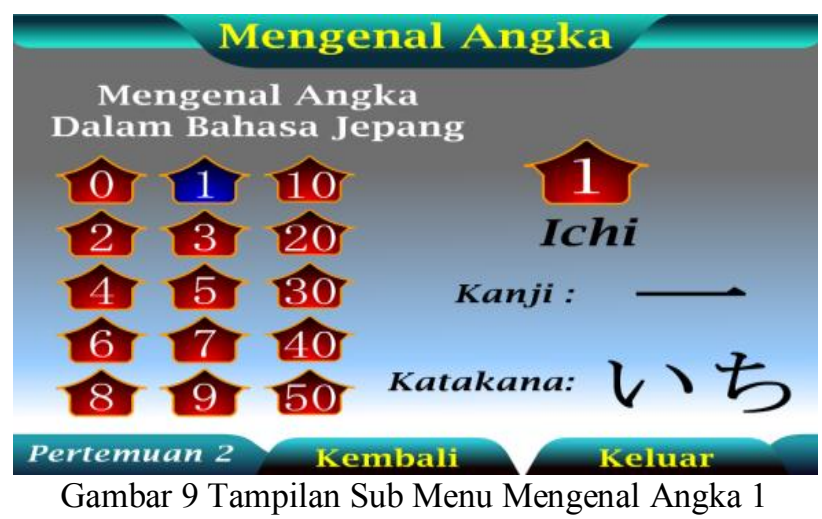

\section{K.Sub Menu Mengenal Angka Dua}

Pada sub menu Mengenal Angka Dua terdapat tulisan Mengenal Angka pada bagian atasnya, dibawahnya dibawahnya terdapat tulisan Mengenal Angka dalam Bahasa Jepang. Pada sub menu ini terdapat 16 tombol, yang terbagi atas dua bagian tombol 0 sampai tombol 50 untuk tombol masuk kedalam angka dalam bahasa Jepang, bagian kedua terdapat tombol Kembali, untuk kembali ke menu utama dan tombol keluar untuk keluar dari program. Pada bagian sebelah kanan terdapat penjelasan tentang angka Dua dalam bahasa Jepang.

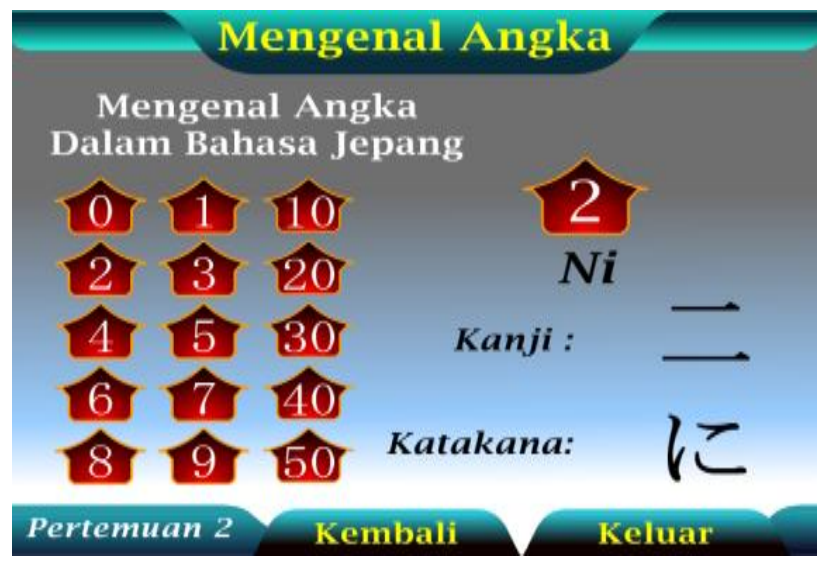

Gambar 10 Tampilan Sub Menu Mengenal Angka 2

\section{Sub Menu Mengenal Angka Tiga}

Pada sub menu Mengenal Angka tiga terdapat tulisan Mengenal Angka pada bagian atasnya, dibawahnya dibawahnya terdapat tulisan Mengenal Angka dalam Bahasa Jepang. Pada sub menu ini terdapat 16 tombol, yang terbagi atas dua bagian tombol 0 sampai 
tombol 50 untuk tombol masuk kedalam angka dalam bahasa Jepang, bagian kedua terdapat tombol Kembali, untuk kembali ke menu utama dan tombol keluar untuk keluar dari program. Pada bagian sebelah kanan terdapat penjelasan tentang angka Tiga dalam bahasa Jepang.

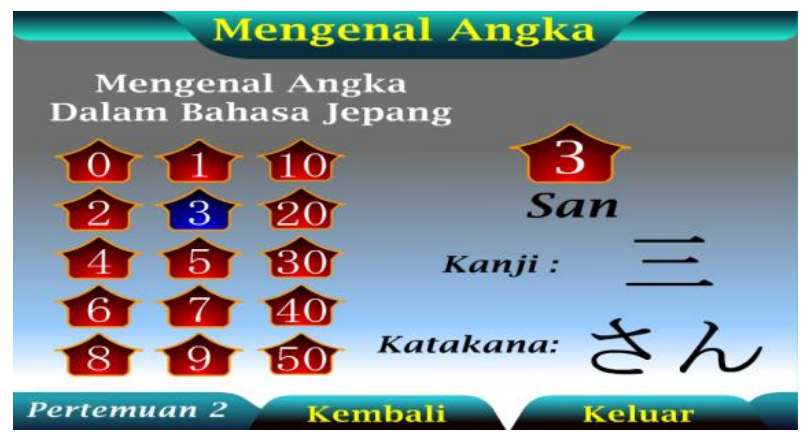

Gambar 11 Tampilan Sub Menu Mengenal Angka 3

\section{M.Sub Menu Mengenal Angka Empat}

Pada sub menu Mengenal Angka empat terdapat tulisan Mengenal Angka pada bagian atasnya, dibawahnya terdapat tulisan Mengenal Angka dalam Bahasa Jepang. Pada sub menu ini terdapat 16 tombol, yang terbagi atas dua bagian tombol 0 sampai tombol 50 untuk tombol masuk kedalam angka dalam bahasa Jepang, bagian kedua terdapat tombol Kembali, untuk kembali ke menu utama dan tombol keluar untuk keluar dari program. Pada bagian sebelah kanan terdapat penjelasan tentang angka empatdalam bahasa Jepang.

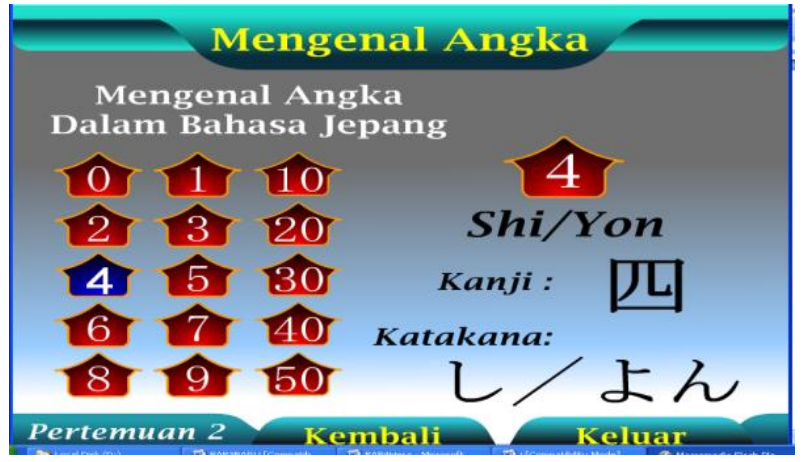

Gambar 12 Tampilan Sub Menu Mengenal Angka 4

\section{N. Sub Menu Mengenal Angka Lima}

Pada sub menu Mengenal Angka lima terdapat tulisan Mengenal Angka pada bagian atasnya, dibawahnya terdapat tulisan Mengenal Angka dalam Bahasa Jepang. Pada sub menu ini terdapat 16 tombol, yang terbagi atas dua bagian tombol 0 sampai tombol 50 untuk tombol masuk kedalam angka dalam bahasa Jepang, bagian kedua terdapat tombol Kembali, untuk kembali ke menu utama dan tombol keluar untuk keluar dari program. Pada bagian sebelah kanan terdapat penjelasan tentang angka lima dalam bahasa Jepang.

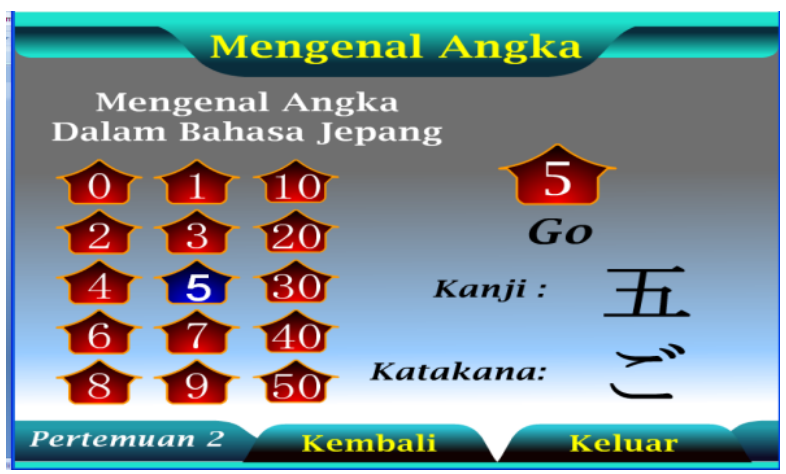

Gambar 13 Tampilan Sub Menu Mengenal Angka 5

\section{O. Sub Menu Mengenal Angka Enam}

Pada sub menu Mengenal Angka Enam terdapat tulisan Mengenal Angka pada bagian atasnya, dibawahnya terdapat tulisan Mengenal Angka dalam Bahasa Jepang. Pada sub menu ini terdapat 16 tombol, yang terbagi atas dua bagian tombol 0 sampai tombol 50 untuk tombol masuk kedalam angka dalam bahasa Jepang, bagian kedua terdapat tombol Kembali, untuk kembali ke menu utama dan tombol keluar untuk keluar dari program. Pada bagian sebelah kanan terdapat penjelasan tentang angka Enam dalam bahasa Jepang.

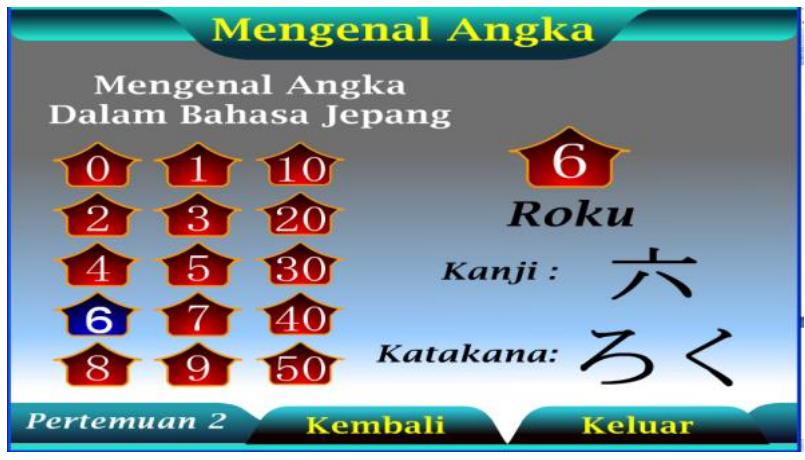

Gambar14 Tampilan Sub Menu Mengenal Angka 6

\section{P.Sub Menu Mengenal Angka Tujuh}

Pada sub menu Mengenal Angka tujuh terdapat tulisan Mengenal Angka pada bagian atasnya, dibawahnya terdapat tulisan Mengenal Angka dalam Bahasa Jepang. Pada sub menu ini terdapat 16 tombol, yang terbagi atas dua bagian tombol 0 sampai tombol 50 
untuk tombol masuk kedalam angka dalam bahasa Jepang, bagian kedua terdapat tombol Kembali, untuk kembali ke menu utama dan tombol keluar untuk keluar dari program. Pada bagian sebelah kanan terdapat penjelasan tentang angka tujuh dalam bahasa Jepang.

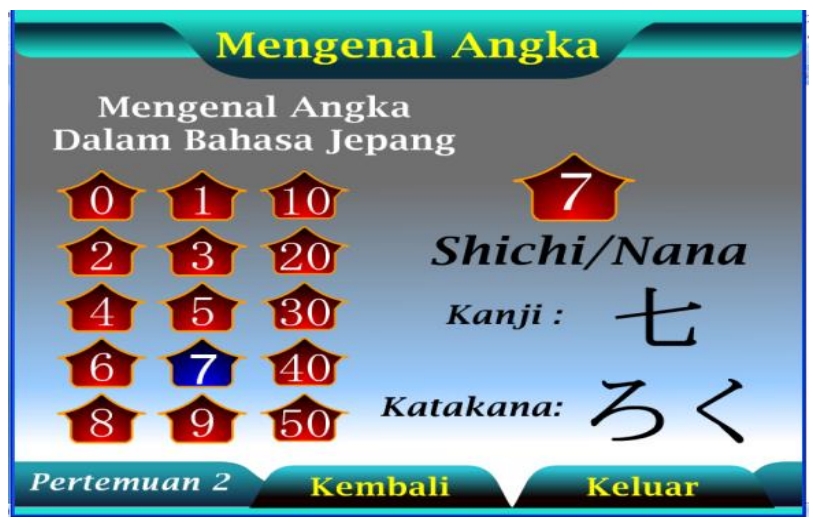

Gambar15 Tampilan Sub Menu Mengenal Angka 7

\section{Q. Sub Menu Mengenal Angka Delapan}

Pada sub menu Mengenal Angka delapan terdapat tulisan Mengenal Angka pada bagian atasnya, dibawahnya terdapat tulisan Mengenal Angka dalam Bahasa Jepang. Pada sub menu ini terdapat 16 tombol, yang terbagi atas dua bagian tombol 0 sampai tombol 50 untuk tombol masuk kedalam angka dalam bahasa Jepang, bagian kedua terdapat tombol Kembali, untuk kembali ke menu utama dan tombol keluar untuk keluar dari program. Pada bagian sebelah kanan terdapat penjelasan tentang angka delapan dalam bahasa Jepang.

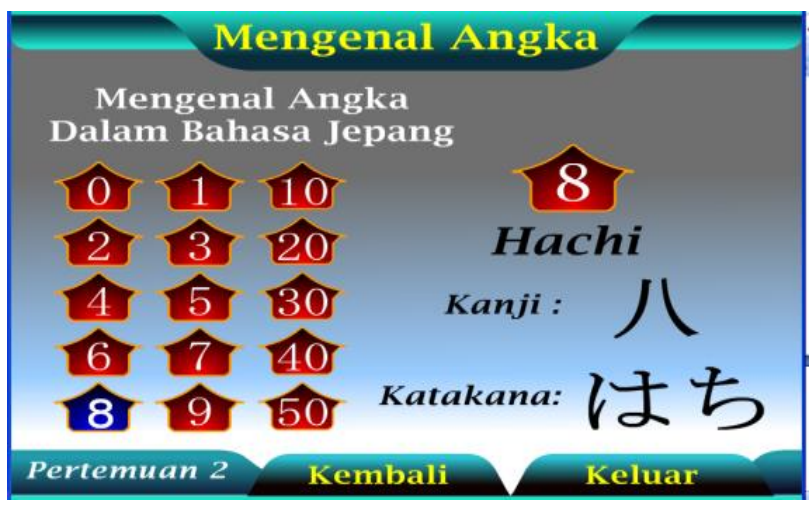

Gambar16 Tampilan Sub Menu Mengenal Angka 8

\section{R. Sub Menu Mengenal Angka Sembilan}

Pada sub menu Mengenal Angka Sembilan terdapat tulisan Mengenal Angka pada bagian atasnya, dibawahnya terdapat tulisan Mengenal Angka dalam Bahasa Jepang. Pada sub menu ini terdapat 16 tombol, yang terbagi atas dua bagian tombol 0 sampai tombol 50 untuk tombol masuk kedalam angka dalam bahasa Jepang, bagian kedua terdapat tombol Kembali, untuk kembali ke menu utama dan tombol keluar untuk keluar dari program. Pada bagian sebelah kanan terdapat penjelasan tentang angka sembilan dalam bahasa Jepang.

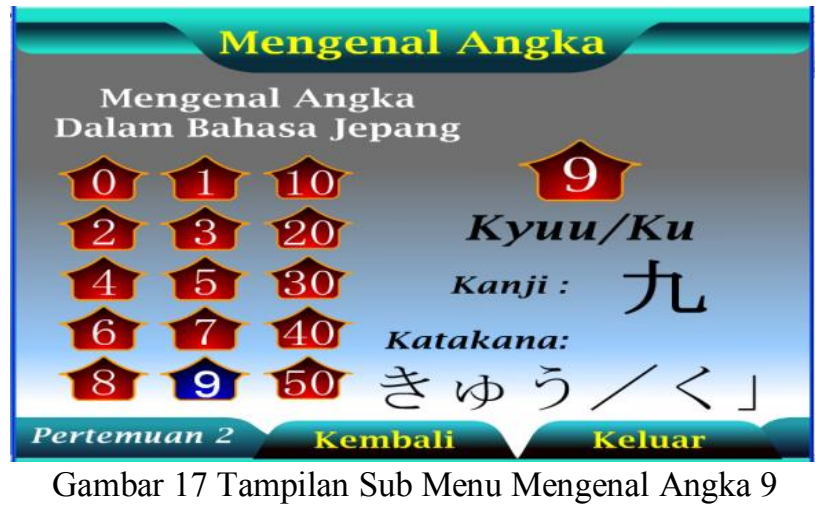

\section{S. Sub Menu Mengenal Angka Sepuluh}

Pada sub menu Mengenal Angka Sepuluh terdapat tulisan Mengenal Angka pada bagian atasnya, dibawahnya terdapat tulisan Mengenal Angka dalam Bahasa Jepang. Pada sub menu ini terdapat 16 tombol, yang terbagi atas dua bagian tombol 0 sampai tombol 50 untuk tombol masuk kedalam angka dalam bahasa Jepang, bagian kedua terdapat tombol Kembali, untuk kembali ke menu utama dan tombol keluar untuk keluar dari program. Pada bagian sebelah kanan terdapat penjelasan tentang angka sepuluh dalam bahasa Jepang.

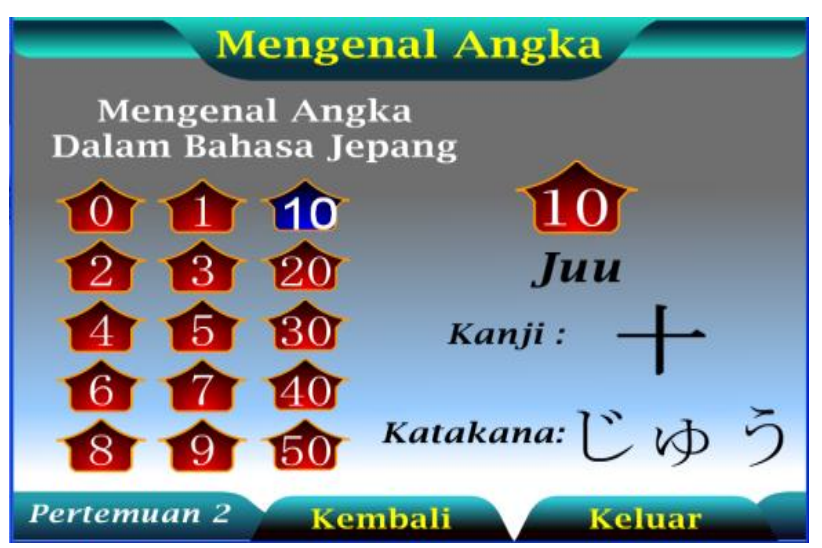

Gambar18 Tampilan Sub Menu Mengenal Angka 10

\section{T. Sub Menu Mengenal Angka Dua Puluh}

Pada sub menu Mengenal Angka dua puluh terdapat tulisan Mengenal Angka pada bagian atasnya, dibawahnya terdapat tulisan Mengenal Angka dalam Bahasa Jepang. Pada sub menu ini terdapat 16 tombol, yang terbagi atas dua bagian tombol 0 sampai tombol 50 
untuk tombol masuk kedalam angka dalam bahasa Jepang, bagian kedua terdapat tombol Kembali, untuk kembali ke menu utama dan tombol keluar untuk keluar dari program. Pada bagian sebelah kanan terdapat penjelasan tentang angka dua puluh dalam bahasa Jepang.

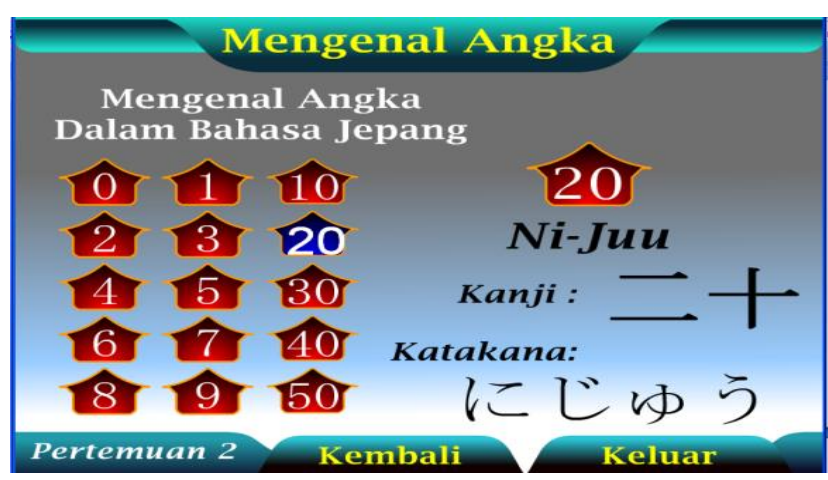

Gambar 19. Tampilan Sub Menu Mengenal Angka 20

\section{U. Sub Menu Mengenal Angka Tiga Puluh}

Pada sub menu Mengenal Angka tiga puluh terdapat tulisan Mengenal Angka pada bagian atasnya, dibawahnya terdapat tulisan Mengenal Angka dalam Bahasa Jepang. Pada sub menu ini terdapat 16 tombol, yang terbagi atas dua bagian tombol 0 sampai tombol 50 untuk tombol masuk kedalam angka dalam bahasa Jepang, bagian kedua terdapat tombol Kembali, untuk kembali ke menu utama dan tombol keluar untuk keluar dari program. Pada bagian sebelah kanan terdapat penjelasan tentang angka tiga puluh dalam bahasa Jepang.

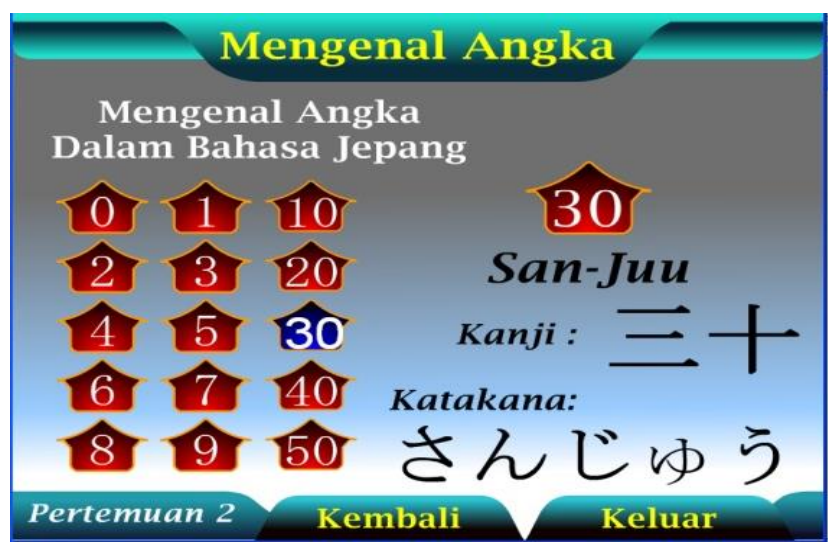

Gambar 20 Tampilan Sub Menu Mengenal Angka 30

\section{Sub Menu Mengenal Angka Empat puluh}

Pada sub menu Mengenal Angka empat puluh terdapat tulisan Mengenal Angka pada bagian atasnya, dibawahnya terdapat tulisan Mengenal Angka dalam Bahasa Jepang. Pada sub menu ini terdapat 16 tombol, yang terbagi atas dua bagian tombol 0 sampai tombol 50 untuk tombol masuk kedalam angka dalam bahasa Jepang, bagian kedua terdapat tombol Kembali, untuk kembali ke menu utama dan tombol keluar untuk keluar dari program. Pada bagian sebelah kanan terdapat penjelasan tentang angka empat puluh dalam bahasa Jepang.

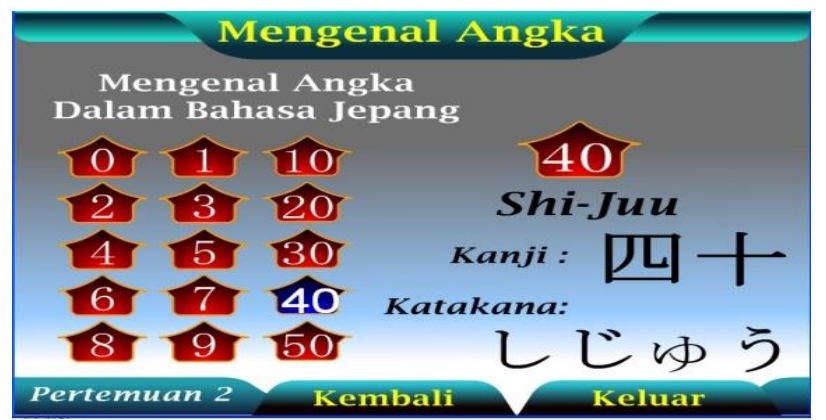

Gambar 21 Tampilan Sub Menu Mengenal Angka 40

\section{W. Sub Menu Mengenal Angka Lima Puluh}

Pada sub menu Mengenal Angka lima puluh terdapat tulisan Mengenal Angka pada bagian atasnya, dibawahnya terdapat tulisan Mengenal Angka dalam Bahasa Jepang. Pada sub menu ini terdapat 16 tombol, yang terbagi atas dua bagian tombol 0 sampai tombol 50 untuk tombol masuk kedalam angka dalam bahasa Jepang, bagian kedua terdapat tombol Kembali, untuk kembali ke menu utama dan tombol keluar untuk keluar dari program. Pada bagian sebelah kanan terdapat penjelasan tentang angka lima puluh dalam bahasa Jepang.

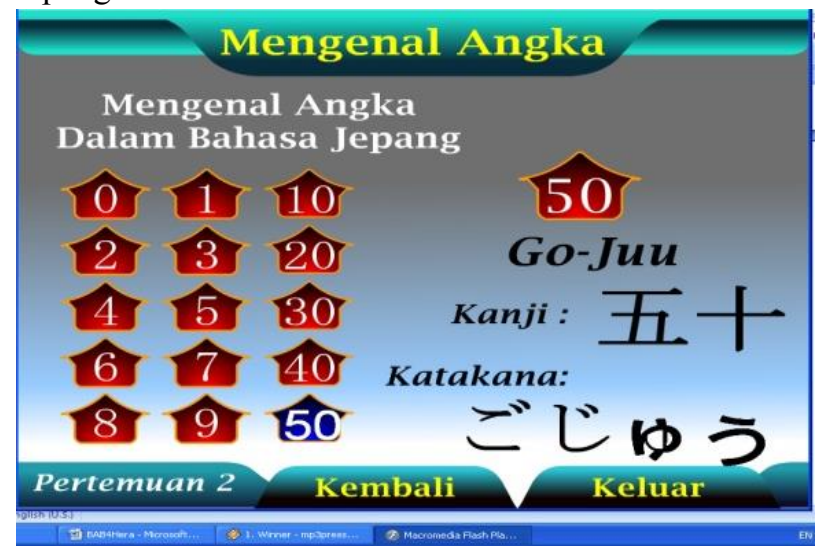

Gambar 22 Tampilan Sub Menu Mengenal Angka 50

\section{Menu Mengenal Bulan}

Pada menu Mengenal bulan terdapat tulisan Mengenal Bulan pada bagian atasnya, Pada sub menu ini 
terdapat 14 tombol, yang terbagi atas dua bagian, tombol Januari sampai tombol Desember untuk tombol masuk kedalam Bulan dalam bahasa Jepang, bagian kedua terdapat tombol Kembali, untuk kembali ke menu utama dan tombol keluar untuk keluar dari program.

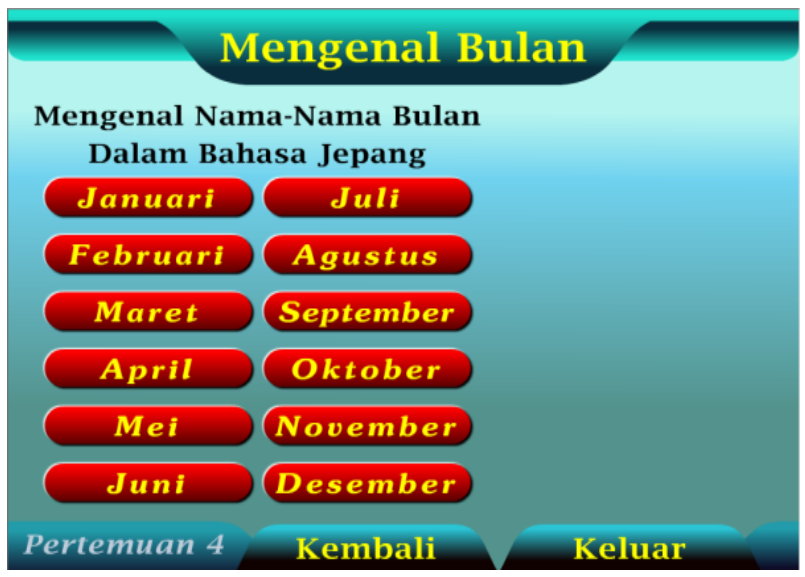

Gambar 23 Tampilan Menu Pembuka

\section{Y. Menu Mengenal Kebudayaan Bonsai}

Pada menu Mengenal kebudayaan terdapat tulisan Mengenal kebudayaan Bonsai, pada sub menu ini terdapat 4 tombol. 2 tombol tanda panah disebelah kiri dan kanan untuk melihat bagian selanjutnya. Tombol kembali untuk kembali ke menu utama dan tombol keluar untuk keluar dari program.

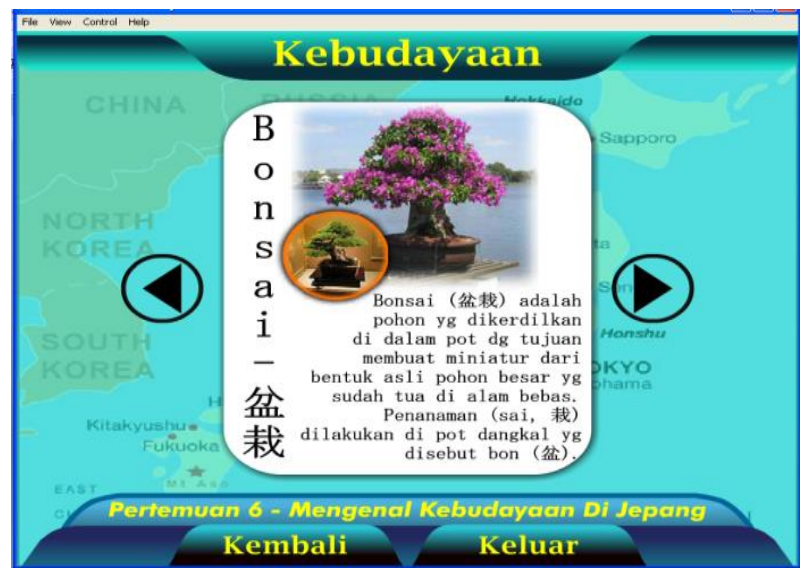

Gambar 24 Tampilan Sub Menu Mengenal Kebudayaan

\section{Bonsai}

\section{Z. Menu Mengenal Kebudayaan Kabuki}

Pada menu Mengenal kebudayaan terdapat tulisan mengenal kebudayaan Kabuki, pada sub menu ini terdapat 4 tombol, 2 tombol tanda panah disebelah kiri dan kanan untuk melihat bagian selanjutnya. tombol kembali untuk kembali ke menu utama dan tombol keluar untuk keluar dari program.

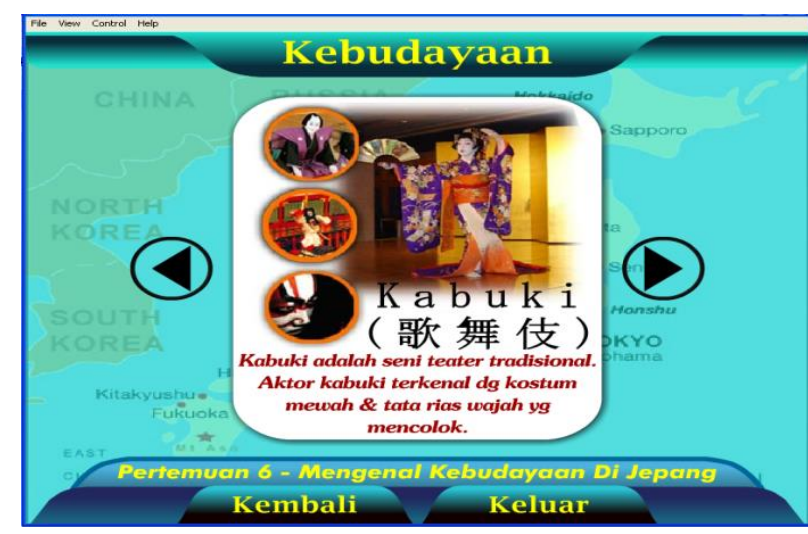

Gambar 25 Tampilan Sub Menu Mengenal

Kebudayaan Kabuki

\section{V.PENUTUP}

A. Kesimpulan

Penelitian ini bertujuan untuk membuat metode pembelajaran bahasa jepang tingkat dasar pada LP2M El Rahma Bengkulu dengan menggunakan Macromedia Flash $M X$, agar mempermudah pengajar, siswa dan mahasiswa dalam mempelajari bahasa jepang tingkat dasar sehingga menambah minat dan daya tarik dalam belajar bahasa jepang.

Penelitian dilaksanakan bagaimana membuat metode pembelajaran bahasa jepang tingkat dasar menggunakan Macromedia Flash MX berupa tampilan animasi berdasarkan kurikulum yang berlaku. Sehingga dapat bermanfaat bagi El Rahma Bengkulu dan siswa dan mahasiswa tentunya.

Hasil dari pengujian sistem, dapat kesimpulan bahwa metode pembelajaran bahasa jepang ini pada LP2M El Rahma Bengkulu, terlebih dahulu membuat perancangan sistem agar mudah memahami, dan software yang digunakan disesuai dengan kebutuhsan saat ini.

B. Saran

1. Pihak lembaga dapat meningkatkan sistem pembelajarannya sehingga baik secara metode yang bagus dan sarana yang mendukung agar dapat menciptakan insan-insan yang berkualitas.

2. Pihak lembaga harus memberikan pelayanan yang bagus terhadap para peserta didik agar kenyamanan dalam menggali ilmu 


\section{DAFTAR PUSTAKA}

[1].Jeprie, M., 2006, Student GuideSseries : Macromedia Flash MX 2004, Elex Media Komputindo, Jakarta.

[2].Hamalik, Oemar. (2001). Proses Belajar Mengajar. Jakarta : Bumi Aksara

[3]Munir. 2013. Multimedia Konsep dan Aplikasi Dalam Pendidikan. Bandung: Alfabeta

[4].Suryanto, Slamet (2003). Konsep Dasar Pendidikan Anak Usia Dini. Yogyakarta: Universitas Negeri Yogyakarta

[5] Suryanto, Slamet (2005). Dasar-dasar Pendidikan Anak Usia Dini. Yogyakarta: Hikayat Publishing 